\title{
Induction of complement proteins in a mouse model for cerebral microvascular $\mathrm{A} \beta$ deposition Rong Fan, Kelly DeFilippis and William E Van Nostrand*
}

Address: Department of Medicine, Stony Brook University, Stony Brook, NY 11794 USA

Email: Rong Fan - Rong.fan@stonybrook.edu; Kelly DeFilippis - Kelly.Ziegler@stonybrook.edu; William E Van Nostrand* - William.VanNostrand@stonybrook.edu

* Corresponding author

Published: 18 September 2007

Journal of Neuroinflammation 2007, 4:22 doi:10.1 I86/I742-2094-4-22
Received: 30 July 2007

Accepted: 18 September 2007

This article is available from: http://www.jneuroinflammation.com/content/4/I/22

(c) 2007 Fan et al; licensee BioMed Central Ltd.

This is an Open Access article distributed under the terms of the Creative Commons Attribution License (http://creativecommons.org/licenses/by/2.0), which permits unrestricted use, distribution, and reproduction in any medium, provided the original work is properly cited.

\begin{abstract}
The deposition of amyloid $\beta$-protein $(A \beta)$ in cerebral vasculature, known as cerebral amyloid angiopathy (CAA), is a common pathological feature of Alzheimer's disease and related disorders. In familial forms of CAA single mutations in the $A \beta$ peptide have been linked to the increase of vascular $A \beta$ deposits accompanied by a strong localized activation of glial cells and elevated expression of neuroinflammatory mediators including complement proteins. We have developed human amyloid- $\beta$ precursor protein transgenic mice harboring two CAA A $\beta$ mutations (Dutch E693Q and lowa D694N) that mimic the prevalent cerebral microvascular $A \beta$ deposition observed in those patients, and the Swedish mutations (K670N/M67IL) to increase $A \beta$ production. In these $\mathrm{Tg}$-SwDI mice, we have reported predominant fibrillar $A \beta$ along microvessels in the thalamic region and diffuse plaques in cortical region. Concurrently, activated microglia and reactive astrocytes have been detected primarily in association with fibrillar cerebral microvascular $A \beta$ in this model. Here we show that three native complement components in classical and alternative complement pathways, $\mathrm{Clq}, \mathrm{C} 3$, and C4, are elevated in Tg-SwDI mice in regions rich in fibrillar microvascular A $\beta$. Immunohistochemical staining of all three proteins was increased in thalamus, hippocampus, and subiculum, but not frontal cortex. Western blot analysis showed significant increases of all three proteins in the thalamic region (with hippocampus) as well as the cortical region, except C3 that was below detection level in cortex. Also, in the thalamic region (with hippocampus), $\mathrm{Cl} q$ and C3 mRNAs were significantly up-regulated. These complement proteins appeared to be expressed largely by activated microglial cells associated with the fibrillar microvascular $A \beta$ deposits. Our findings demonstrate that $\mathrm{Tg}$-SwDI mice exhibit elevated complement protein expression in response to fibrillar vascular $A \beta$ deposition that is observed in patients with familial CAA.
\end{abstract}

\section{Background}

Abnormal accumulation of amyloid $\beta$ peptides $(A \beta)$ in brain is one of the major pathological characterizations of Alzheimer's disease (AD) and related disorders [1]. A $\beta$, a $39-42$ residue proteolytic product of the amyloid- $\beta$ peptide precursor (A $\beta \mathrm{PP})$ by $\beta$ - and $\gamma$-secretase cleavages, possesses a high propensity to self-assemble into $\beta$ sheet-rich fibrils [2]. One prominent site of brain $A \beta$ deposition is in and along the walls of cerebral blood vessels, a condition known as cerebral amyloid angiopathy (CAA), which is frequently found in $\mathrm{AD}[3,4]$. In contrast to parenchymal plaques, which can be composed of either diffuse or fibrillar deposits, cerebral vascular $A \beta$ deposits appear to be exclusively fibrillar in nature [5]. Several familial forms of 
CAA result from specific point mutations within the midregion of the $A \beta$ domain, which significantly enhance the fibrillogenic and cerebral vascular cytotoxic properties of A $\beta$ [6-8].

Previously, we generated transgenic mice that express neuronally derived human $\mathrm{A} \beta \mathrm{PP}$, containing the Dutch-type (E693Q) and Iowa-type (D694N) familial CAA mutations, the Tg-SwDI mice [9]. These mice were shown to develop early-onset and robust deposition of cerebral microvascular fibrillar amyloid but only diffuse parenchymal $A \beta$ plaques. The microvascular accumulation of fibril$\operatorname{lar} \mathrm{A} \beta$ is most prominent in the thalamic and subiculum regions of the brain [9]. In these areas with the most fibrillar microvascular $A \beta$ deposits, activated inflammatory cells, microglia and astrocytes, were also found highly enhanced [10]. Several pro-inflammatory cytokines were shown to be elevated in Tg-SwDI mouse brains, indicating the active synthesis of inflammatory molecules by these cells $[10,11]$.

Another important aspect of the neuroinflammatory response in $\mathrm{AD}$ and $\mathrm{CAA}$ is the innate immune system activation, among which, complement is a key player [12]. Complement proteins have been shown to be induced and associated with $\mathrm{A} \beta$ plaques in brains of $\mathrm{AD}$ patients and familial CAA patients as well as AD animal models, specifically those plaques containing the fibrillar form of the $A \beta$ peptide [13-15]. The overall outcome of complement activation depends on the balance of its detrimental and beneficial effects [16]. On one side, complement activation could induce cell lysis and cause cell death $[17,18]$; on the other side, complement components such as $\mathrm{C} 1 \mathrm{q}$ and $\mathrm{C} 3 \mathrm{~b}$ can promote the clearance of cellular debris and apoptotic cells and enhance cell survival $[15,19]$. Although complement proteins are typically secreted by immune cells, in the CNS, microglia, astrocytes, and neurons have been reported being capable of producing complement components upon stimulation $[20,21]$. In the current study, we investigated the expression of several native complement components in twelve months old Tg-SwDI and wild-type C57BL/6 mice, and found they were increased significantly in association with microvascular amyloid deposits and co-localized with activated microglial cells. The finding that microglial synthesis of the native complement proteins was induced suggests that early complement activation may be increased in the Tg-SwDI mouse model of cerebral microvacular $A \beta$ deposition.

\section{Methods \\ Animals}

Generation of Tg-SwDI transgenic mice on a pure C57BL/ 6 background was recently described [9]. These mice express low levels of human Swedish/Dutch/Iowa mutant
А $\beta P P$ in neurons under control of the mouse Thy 1.2 promoter. The deposition of mutant Dutch/Iowa $A \beta$ peptide starts around 3 months of age and begins to plateau at about 15 months in transgenic mice with low variation between individuals. Homozygous Tg-SwDI and nontransgenic C57BL/6 mice at 12 months of age were used in this study. All work with animals followed National Institutes of Health guidelines and was approved by Stony Brook University Institutional Animal Care and Use Committee.

\section{Histology}

At least 24 mice per genotype were euthanized at 12 months of age. After cold-phosphate buffer saline (PBS, $0.1 \mathrm{M}, \mathrm{pH}$ 7.6) perfusion, brains were removed and dissected through the mid-sagittal plane. One cerebral hemisphere was immersion-fixed with $4 \%$ paraformaldehyde overnight at $4{ }^{\circ} \mathrm{C}$ and subjected to increasing concentrations $(10,20$, and $30 \%)$ of sucrose in PBS, then embedded in OCT compound (Sakura Finetek Inc., Torrance, CA) and snap-frozen in dry ice. Coronal sections were cut at $20-\mu \mathrm{m}$ thickness using a Leica CM1900 cryostat (Leica Microsystems, Inc., Bannockburn, IL), and then stored in PBS with $0.02 \% \mathrm{NaN}_{3}$ at $4{ }^{\circ} \mathrm{C}$.

\section{Immunohistochemistry}

Immunostainings were performed on sections mounted on Colorfrost/Plus slides (Fisher Scientific, Houston, TX). Antigen retrieval was performed in 1:100 antigenunmasking solution (Vector Lab, Burlingame, CA) for 30 min at $90^{\circ} \mathrm{C}$ for $\mathrm{C} 1 \mathrm{q}$ and microglia immunostaining. Nonspecific binding was prevented by incubating sections in blocking buffer (PBS containing 0.1\% Triton X-100 and $2 \%$ bovine serum albumin (Sigma, St. Louis, MO) for 20 min at room temperature. Brain sections were incubated with primary antibodies diluted in blocking buffer overnight at $4{ }^{\circ} \mathrm{C}$. The following primary antibodies were used for immunostaining: mouse monoclonal antibody to glial fibrillary acidic protein (GFAP) for identification of astrocytes (1:300, Millipore, Temecula, CA); mouse monoclonal antibody 5D4 to keratan sulfate for identification of activated microglia (1:300; Seikagaku Corporation, Japan); monoclonal rat-anti-mouse C3 (1:500) and monoclonal rat-anti-mouse C4 (1:1000, Cedarlane, Burlington, NC); polyclonal rabbit-anti-mouse C1q (1:500, generous gift from Dr. Andrea J Tenner, University of California, Irvine). Biotinylated donkey anti-rat IgG and donkey anti-rabbit IgG (both at 1:200, Vector Lab), followed by Fluor590-conjugated streptavidin (1:500, Invitrogen, Carlsbad, CA) and Fluor488-conjugated anti-mouse antibody (1:500, Invitrogen) were used for immuno-detection.

The brain sections were examined using an Olympus BX60 fluorescent microscope (Olympus America Inc., 
Center Valley, PA) with Olympus DP10 camera (Olympus) and ASI MS-2000 motorized stage (Applied Scientific Instruments, Eugene, OR). Pictures were taken with 10x eye-piece and 40x objective.

\section{Western blot}

Micro-dissected tissue was removed from the thalamic (with hippocampus) and cortical (frontal cortex) brain regions of 12-months old Tg-SwDI and non-transgenic $(\mathrm{C} 57 \mathrm{BL} / 6)$ mice (from the other hemisphere of the same animals used for histology). Half of each group were homogenized on ice in lysis buffer containing 1\% SDS, $0.5 \%$ IGPEL in PBS with Complete protease inhibitor (Roche, Basel, Switzerland) at $10 \mathrm{ml} / \mathrm{g}$ tissue ratio. The protein concentration was determined using the bichinchonic acid method (Pierce, Rockford, IL). Equal amounts of protein $(50 \mu \mathrm{g})$ were loaded, fractionated on $10 \%$ SDSpolyacrylamide gels, and subsequently electrophoretically transferred to nitrocellulose membranes (Schleicher and Schuell, Hertogen-bosch, Netherlands) in blotting buffer (25 mM Tris-HCl, pH 8.6, $192 \mathrm{mM}$ glycine, and $20 \%$ methanol). Blots were washed for $15 \mathrm{~min}$ in PBS containing $0.05 \%$ Tween 20 (PBST), pre-incubated with blocking solution ( $5 \%$ non-fat milk powder in PBST), washed three times with PBST, and subsequently incubated with primary antibodies and peroxidase-labeled secondary goat anti-rat or donkey anti-rabbit antibodies (Dako, Glostrup, Denmark). Detection was performed by chemiluminescence according to the description of the manufacturer (Boehringer Mannheim, Almere, Netherlands) and exposed to Kodak (Rochester, NY) X-OMAT-R films and quantified using VersaDoc imaging system (BioRad, Hercules, CA). The molecular mass of specific bands was determined by comparing to the BenchMark pre-stained protein ladder (Invitrogen) electrophoresed on the same gels.

Real-time reverse transcriptase polymerase chain reaction Total RNA was isolated from the tissue using RNeasy Lipid Tissue Kit (Qiagen, Hilden, Germany) as per manufacturer's instructions. Single stranded cDNA was prepared using $10 \mu \mathrm{l}$ of total RNA using iScript cDNA Synthesis Kit (Biorad) per manufacturer's instructions. 6-carboxyfluorescein (FAM) 5' end labeled Taqman Assay on Demand primer and probe sets (Applied Biosystems, Foster City, CA) were used to assess expression levels of $\mathrm{C} 1 \mathrm{q}$ (Mm00437836_m1) and C3 (Mm01232773_m1) for each cDNA sample. All samples were normalized against the endogenous control, TATA box binding protein (Mm00446973_m1). 500 ng of each cDNA sample was used in conjunction with 8 pmoles of each primer/probe set plus Taqman Universal Master Mix (Applied Biosystems). Each sample was analyzed in triplicates. Real-time quantitative PCR was performed on an Opticon2 (Biorad) using the following program: $95^{\circ} \mathrm{C}$ for $10 \mathrm{sec}$, followed by
40 cycles of denaturation, $95^{\circ} \mathrm{C}$ for $15 \mathrm{sec}$ and anneal/ elongation, $60^{\circ} \mathrm{C}$ for $1 \mathrm{~min}$. The relative expression level of $\mathrm{C} 1 \mathrm{q}$ or $\mathrm{C} 3$ was computed with respect to the mRNA expression of the endogenous control using the following formula: Relative mRNA expression $=2-(-\mathrm{Ct}$ gene of interest-Ct TATA)

Ct is the threshold cycle value $[22,23]$.

\section{Statistical analysis}

Biochemical and molecular data were analyzed by ANOVA single factor test at $\alpha=0.05$ significance level.

\section{Results}

\section{$\mathrm{Clq}, \mathrm{C3}$, and $\mathrm{C4}$ were induced in $\mathrm{Tg}-\mathrm{SwDI}$ mice}

In our previous studies, we showed that in Tg-SwDI mice, thioflavin-S positive fibrillar $A \beta$ deposits were primarily found to be associated with the microvasculature in the thalamus, subiculum, as well as hippocampus [9]. However, in the cortex $A \beta$ deposits were largely in the parenchyma and in diffuse form. In the transgenic mice, activation of microglia and astrocytes was also elevated along with the microvascular fibrillar $A \beta$ accumulation in the thalamic and hippocampal regions [10]. Since complement proteins have been reported to be present in reactive inflammatory cells associated with amyloid deposits, we first examined the presence of the three early native complement components in different brain regions of $\mathrm{Tg}$ SwDI and wild-type C57BL/6 mice and their relationship with fibrillar $A \beta$ deposits in the transgenic mice. Brains from twelve months old mice were harvested and processed as described in Materials and Methods. Immunostaining for $\mathrm{C} 1 \mathrm{q}$ revealed very little cellular labeling in either the cortex of transgenic animals (Fig 1A) or the entire C57BL/ 6 wild-type mouse brain (data not shown). However, in thalamic region of Tg-SwDI mouse brains (Fig 1B), C1q was present in many cells associated with the microvascular fibrillar amyloid. Similarly, there were minimal immunoreactivities for either $\mathrm{C} 3$ or $\mathrm{C} 4$ in the cortical region of Tg-SwDI (Fig $1 \mathrm{C}$ and $1 \mathrm{E}$, respectively) or any region of $\mathrm{C} 57 \mathrm{BL} / 6$ mice (data not shown), but strong staining in the thalamus of Tg-SwDI mice (Fig 1D and 1F, respectively). Increased immunostaining of $\mathrm{C} 1 \mathrm{q}, \mathrm{C} 3$, and C4 was also detected in hippocampus and subiculum (data not shown), another two regions with prominent fibrillar $\mathrm{A} \beta$ deposition.

\section{Complement proteins are synthesized in Tg-SwDI mouse brain}

Many studies have demonstrated that complement components can be generated locally in brain. Given that no prominent hemorrhage or compromised blood brain barrier has been observed in Tg-SwDI mice, the elevated expression of cerebral complement components is unlikely from peripheral leakage. To test this hypothesis, 
$\mathrm{C} 1 \mathrm{q}$
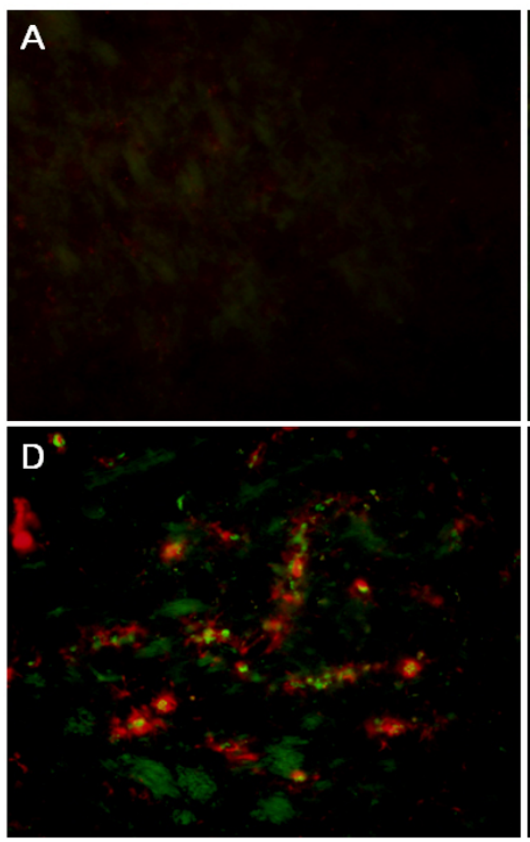

C3
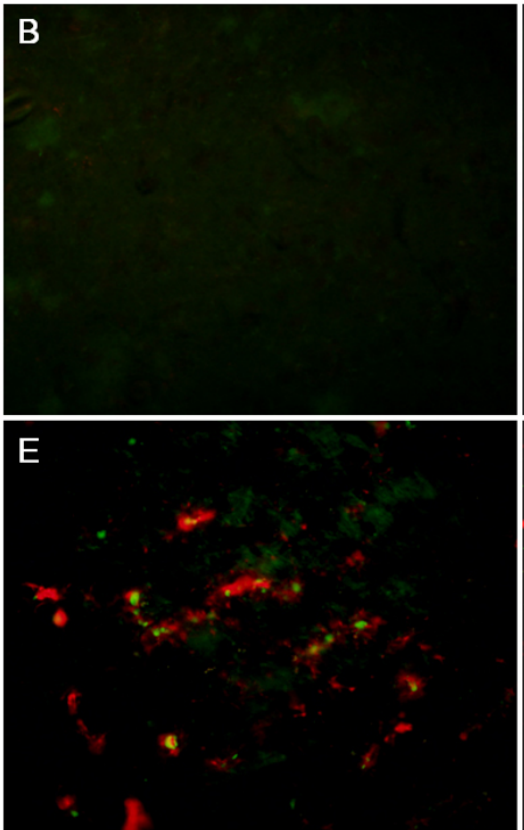

C4

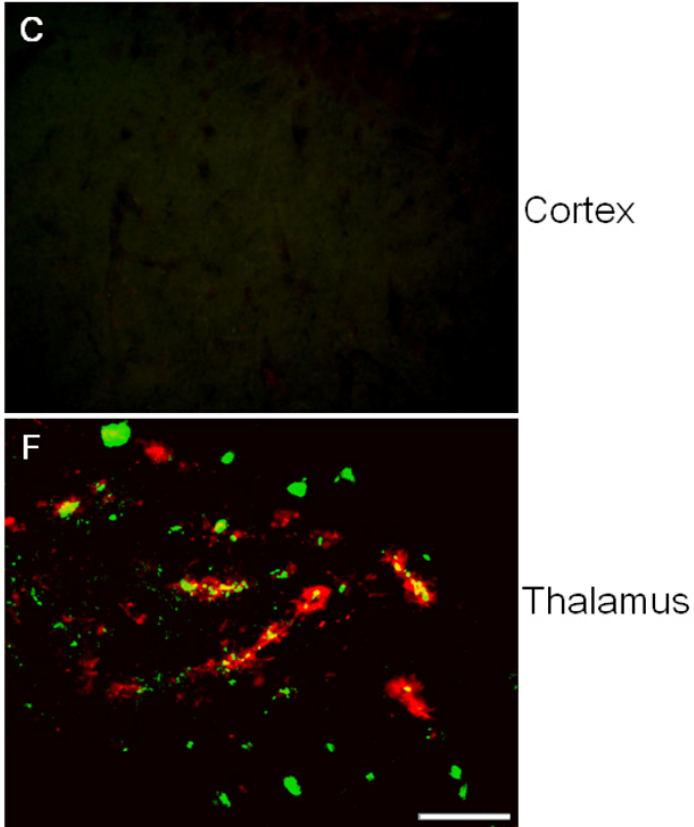

\section{Figure I}

Immunoreactivities of native complement proteins Clq (A, D), C3 (B, E), and C4 (C, F) expressions were elevated in Tg-SwDI mice over wild-type. Forebrains of twelve months old Tg-SwDI and C57BL/6 mice were stained for fibrillar A $\beta$ using thioflavin$S$ amyloid staining (green) and every one of the three complement proteins with specific antibodies (red). Positive complement immunoreactivity was associated with amyloid staining seen in thalamic regions $(D, E, F)$, but not in cortical regions $(A, B, C)$. Scale bars $=50 \mu \mathrm{m}$.

we next investigated the messenger RNA productions of these proteins to determine that the increase of complement expression was due to local synthesis. Quantitative real-time PCR was performed for $\mathrm{C} 1 \mathrm{q}$ and $\mathrm{C} 3$ on mRNAs extracted from micro-dissected brain regions, using TATA box binding protein as the housekeeping gene. The data showed that there was a significant increase $(\mathrm{p}<0.02)$ in the mRNA levels of both $\mathrm{C} 1 \mathrm{q}$ and $\mathrm{C} 3$ in the thalamic regions of Tg-SwDI over wild-type (Fig 2). The increase in cortex of C3 mRNA was also statistically significant ( $\mathrm{p}<$ 0.02), but not of C1q mRNA (Fig 2). To confirm that the increase in mRNA was translated into changes in protein levels, we performed quantitative Western blot analysis for these three complement proteins on homogenates from micro-dissected thalamic and cortical regions. In thalamic region, the results were consistent with both the immunohistochemical and real-time PCR data that protein levels of C1q (Fig 3A), C3 (Fig 3B), and C4 (Fig 3C) were statistically significantly higher $(\mathrm{p}<0.01)$ in $\mathrm{Tg}$ SwDI mice compared to C57BL/6 mice. In cortex, C1q and $\mathrm{C} 4$, but not C3 (undetectable in either genotype), were also significantly elevated $(\mathrm{p}<0.01)$ in $\mathrm{Tg}$-SwDI mice.

\section{Complement proteins are expressed in activated microglia of Tg-SwDI mice}

In Tg-SwDI mice, we previously reported that activated microglia and astrocytes were greatly enhanced in association with microvascular fibrillar $A \beta$, thus were most dense in the thalamic and hippocampal regions rich in these deposits. Both microglia and astrocytes, when activated, can produce many complement components. In order to investigate the cell types that were responsible for the induction of complement synthesis in Tg-SwDI mice, brain sections were immunolabeled for both complement proteins and markers of activated microglia or reactive astrocytes. The cells positive for complement proteins morphologically resembled activated microglial cells. When fluorescent images of both stainings were merged, it was clear that while almost no astrocytes were positive for any of the three complement proteins (Fig 4), most of the complement-positive cells were strongly labeled with antibody for activated microglia (Fig 4). Again, in hippoc- 

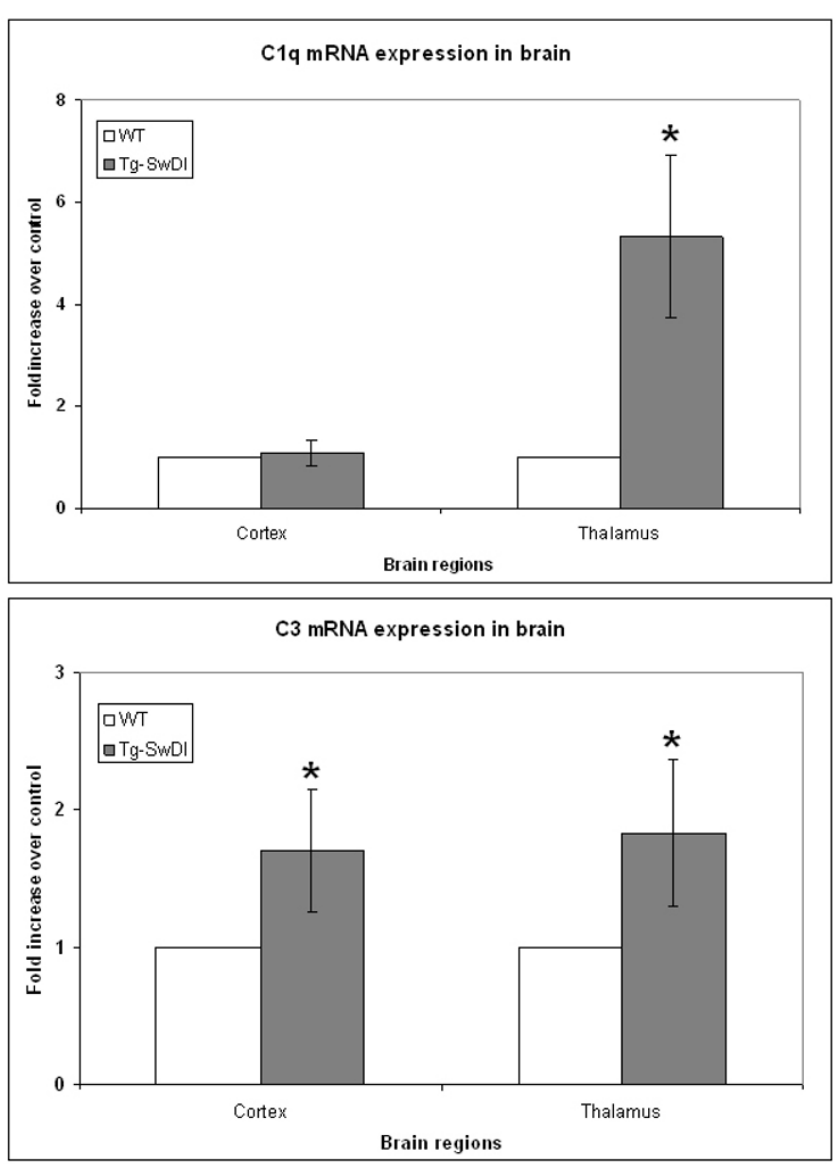

Figure 2

$\mathrm{Clq}$ and $\mathrm{C} 3 \mathrm{mRNAs}$ were increased in Tg-SwDI mouse brains. Real-time PCRs for $\mathrm{Clq}(\mathrm{A})$ and $\mathrm{C} 3$ (B) were performed on cDNAs synthesized from mRNAs extracted from twelve months old C57BL/6 (white bars) and Tg-SwDI (gray bars) mouse cortical and thalamic regions. Data shown are mean \pm S.D. $(n=9)$. Both $\mathrm{Clq}$ and $\mathrm{C} 3$ were statistically significantly higher in transgenic mice over wild-type $\left(*_{p}<0.02\right)$ except $\mathrm{Clq}$ in cortex.

ampus and subiculum, C1q, C3, and C4 immunoreactivities were also greatly overlapped with microglial cells, not astrocytes (data not shown).

\section{Discussion}

We have reported before that in Tg-SwDI mice, in spite of the low expression level of transgene encoded human $\mathrm{A} \beta \mathrm{PP}$, profuse fibrillar amyloid deposits were present in cerebral microvessels, likely due to the highly fibrillogenic property of the Dutch/Iowa CAA mutant A $\beta$ peptide, with no detectable export of this $A \beta$ into the periphery [9]. In association with the microvascular fibrillar $A \beta$ deposits, reactive microglia and astrocytes were found in these animals, and increased with age in parallel to the microvascular $A \beta$ deposition [10]. We also detected proinflammatory cytokines such as TNF $\alpha$, IL-1 $\beta$, and IL-6 to

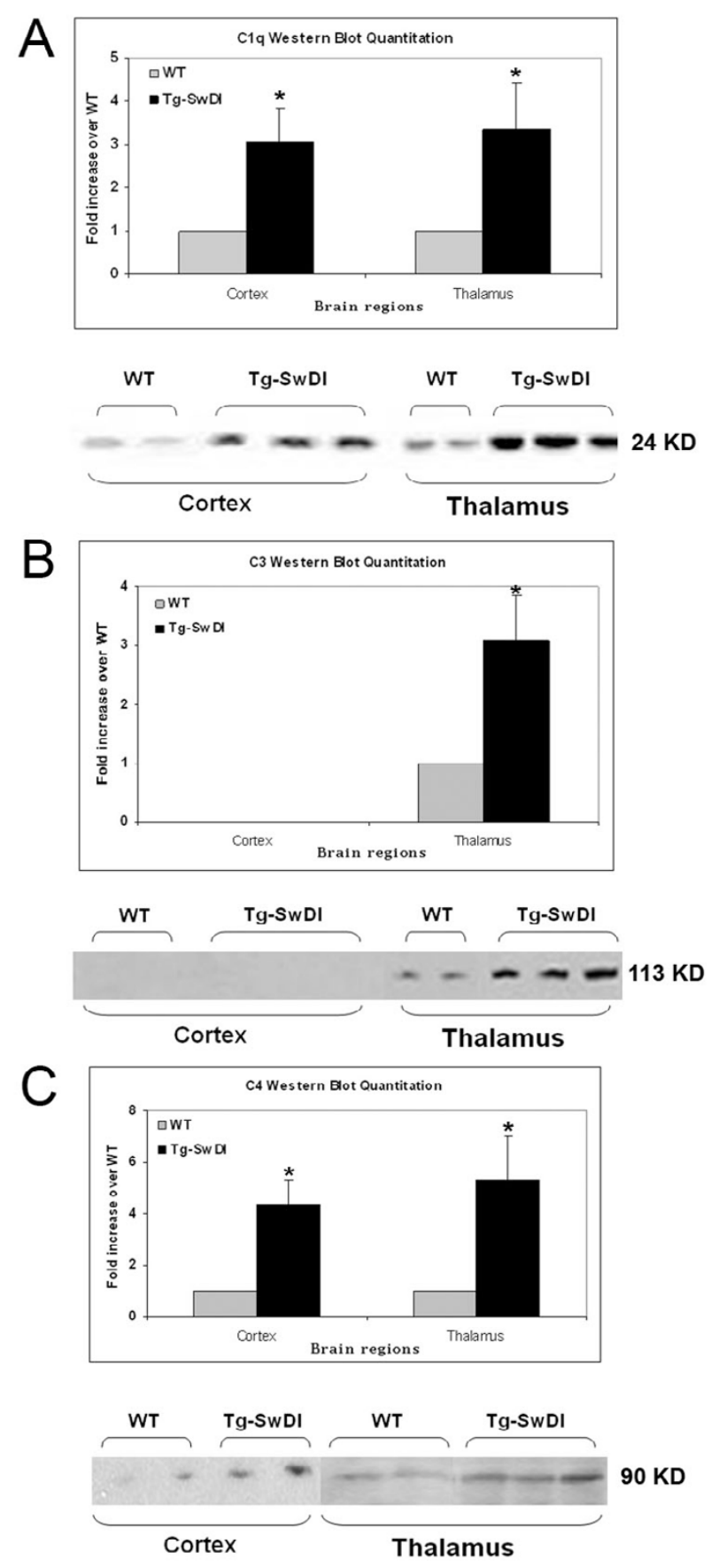

Figure 3

$\mathrm{Clq}, \mathrm{C3}$, and C4 protein levels are elevated in Tg-SwDI mice thalamic region. Western blot analysis of complement proteins was performed using rabbit anti-Clq $(A)$, rat anti-C3 $(B)$, and rat anti-C4 (C) antibodies. Data shown are mean \pm S.D. $(n \geq 6)$. The increase of all three proteins in both regions of the transgenic over wild-type reached statistical significance $(* p<0.01)$ except C3 was undetectable in cortex. Representative western blots are shown below the quantitation. 
$\mathrm{C} 1 \mathrm{q}$
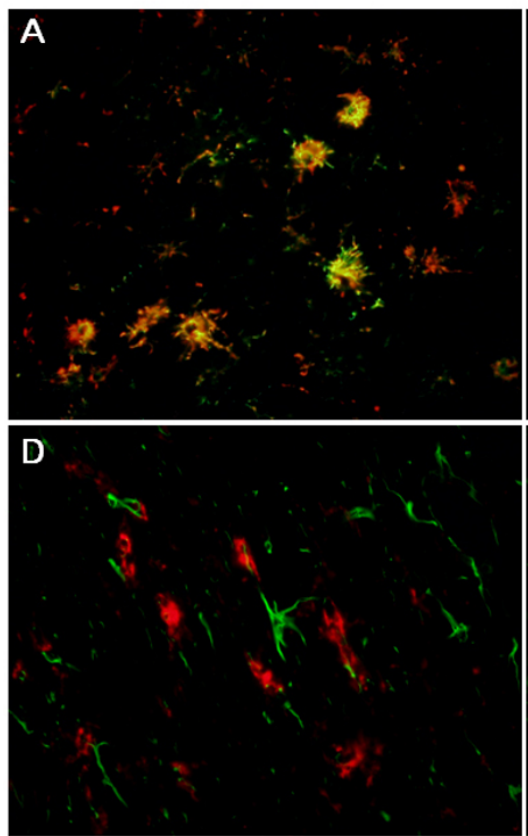

C3
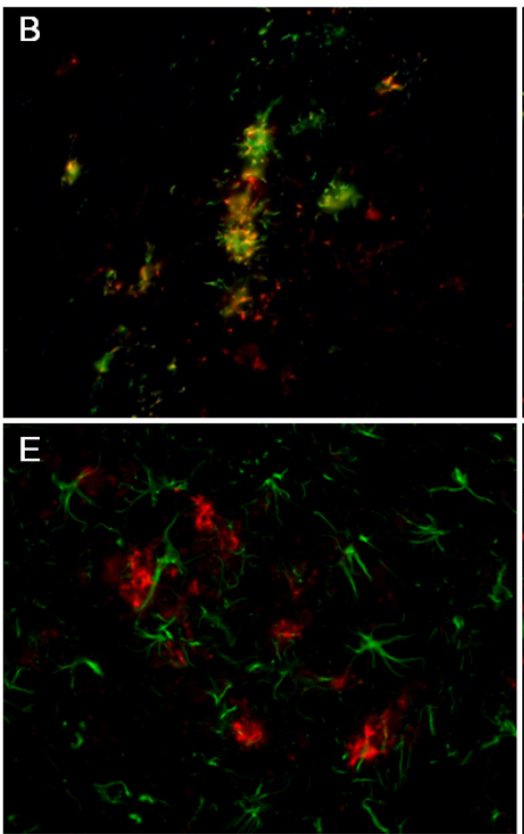

C4
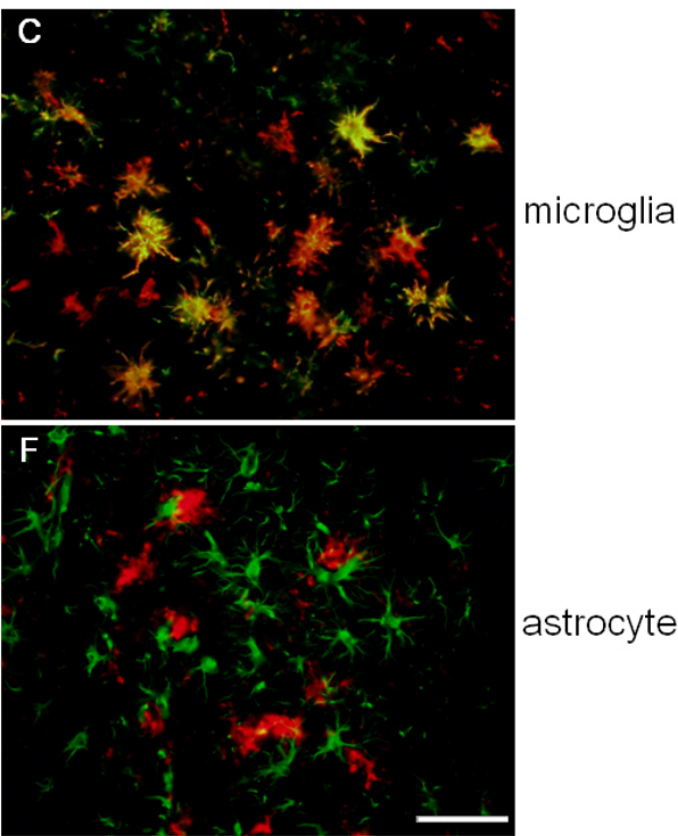

Figure 4

$\mathrm{Clq}, \mathrm{C} 3$, and C4 are expressed in activated microglia not astrocytes. Colocalization of activated microglial cells (green A,B,C) or reactive astrocytes (green D,E,F) and complement components Clq (red A,D), C3 (red B,E), and C4 (red C,F) in the thalamic regions of twelve months old Tg-SwDI mice. Scale bars $=50 \mu \mathrm{m}$.

be enhanced in Tg-SwDI mice, suggesting that these activated cells are actively expressing inflammatory molecules surrounding the microvasculature [10,11]. Previously, it has been shown that complement components are induced in AD patients and familial CAA patients as well as brains of $\mathrm{AD}$ animal models [24]. In addition to the well-studied pathogen elimination by complement activation, amyloid clearance may be promoted by $\mathrm{C} 1 \mathrm{q}$ binding to fibrillar amyloid deposits, and generation of an opsonin, the C3b fragment $[15,25]$. Human studies have also shown increasing complement staining with growing presence of CAA [26]. However, due to the inefficient binding of mouse $\mathrm{C} 1 \mathrm{q}$ to human $\mathrm{A} \beta$, complement activation is much less in mouse models for $\mathrm{AD}$ than in $\mathrm{AD}$ patients [27], which might explain why we did not observe the presence of late-stage complement activation products. In brain, activated microglia are the major source of complement proteins in brain, although reactive astrocytes and neurons have also been shown to express complement when stimulated $[28,29]$.

Here we demonstrate that early native classical complements $\mathrm{C} 1 \mathrm{q}$ and $\mathrm{C} 4$, as well as $\mathrm{C} 3$, an important player in both classical and alternative complement pathways, are up-regulated in Tg-SwDI mouse brains. This induction was likely due to local synthesis since we have detected the increase in messenger RNA and protein levels by real-time PCR technique and Western blot, respectively. The observed differences between mRNA and protein levels of C1q and C3 were possibly due to several reasons. For example, increased levels of certain complement proteins may reflect decreased turnover and/or accumulation with amyloid deposits in the absence of increased expression. Also, the sensitivities of real-time PCR and Western blot are different depending on primers and antibodies, and the message levels may not be translated linearly to protein expression.

The immunoreactivities of $\mathrm{C} 1 \mathrm{q}, \mathrm{C} 3$, and $\mathrm{C} 4$ were cell associated and appeared to track along cerebral microvascular amyloid deposits, particularly in thalamus and subiculum (data not shown). We then investigated the cell type that expressed the complement. Double immunofluorescent labeling indicated that most complement-positive cells were activated microglia, not astrocytes. Although not all complement-positive cells overlapped with activated microglial labeling, this was possibly due to the multiple activation stages and types of microglia and one activation marker (keratan sulfate in this case [30,31] may not reflect all activated microglial cells. These findings further support the notion that microglia in the Tg-SwDI mouse model are actively participating in the neuroinflamma- 
tory response and provide more insight into the specific reactions of microglia during disease progression as well as modulations of these reactions. In light of our recent work in which we detected improvement of memory performance in animals when microglial activation was suppressed [11], the effect of that inhibition on complement induction remains to be investigated to further elucidate the function of elevated complement in this model.

\section{Conclusion}

In summary, complement proteins C1q, C3, and C4 were induced in Tg-SwDI mice in proximity to the cerebral microvasculature. This increase in expression was primarily in thalamus and hippocampus, and also in subiculum by immunohistochemistry (data not shown), regions that contain the highest amount of fibrillar microvascular amyloid deposition. These complement proteins were locally synthesized in brain, and mostly by activated microglial cells associated with microvascular $A \beta$ deposits.

\section{Competing interests}

The author(s) declare that they have no competing interests.

\section{Authors' contributions}

RF processed the animal tissue, performed immunohistochemistry and Western blot, analyzed the data, and drafted the manuscript. KD performed the real-time PCR analysis. WVN contributed to the design of the study, guided data interpretation and presentation and edited the manuscript. All authors have read and approved the final manuscript.

\section{Acknowledgements}

This work is supported by NIH grants NS55 I I 8 and NS36645. The authors thank Ms. Judianne Davis for her input in modifying real-time PCR protocols and Dr. Feng Xu for helping with collecting animal brains. Special thanks to Dr. Andrea J. Tenner at University of California, Irvine for providing the anti-Clq antibody.

\section{References}

I. Walsh DM, Selkoe DJ: Deciphering the molecular basis of memory failure in Alzheimer's disease. Neuron 2004, 44(I): 181 - 193.

2. Hardy J, Selkoe DJ: The amyloid hypothesis of Alzheimer's disease: progress and problems on the road to therapeutics. Science (New York, NY 2002, 297(5580):353-356.

3. Wilcock DM, Gordon MN, Morgan D: Quantification of cerebral amyloid angiopathy and parenchymal amyloid plaques with Congo red histochemical stain. Nature protocols 2006, I(3): I591-1595.

4. Attems J, Quass M, Jellinger KA, Lintner F: Topographical distribution of cerebral amyloid angiopathy and its effect on cognitive decline are influenced by Alzheimer disease pathology. Journal of the neurological sciences 2007, 257(I-2):49-55.

5. Revesz T, Ghiso J, Lashley T, Plant G, Rostagno A, Frangione B, Holton JL: Cerebral amyloid angiopathies: a pathologic, biochemical, and genetic view. Journal of neuropathology and experimental neurology 2003, 62(9):885-898.
6. Levy E, Carman MD, Fernandez-Madrid IJ, Power MD, Lieberburg I, van Duinen SG, Bots GT, Luyendijk W, Frangione B: Mutation of the Alzheimer's disease amyloid gene in hereditary cerebral hemorrhage, Dutch type. Science (New York, NY 1990, 248(4959): I I 24- I I 26.

7. Levy E, Haltia M, Fernandez-Madrid I, Koivunen O, Ghiso J, Prelli F, Frangione B: Mutation in gelsolin gene in Finnish hereditary amyloidosis. The Journal of experimental medicine 1990, |72(6): |865-1867.

8. Grabowski TJ, Cho HS, Vonsattel JP, Rebeck GW, Greenberg SM: Novel amyloid precursor protein mutation in an lowa family with dementia and severe cerebral amyloid angiopathy. Annals of neurology 200I, 49(6):697-705.

9. Davis J, Xu F, Deane R, Romanov G, Previti ML, Zeigler K, Zlokovic BV, Van Nostrand WE: Early-onset and robust cerebral microvascular accumulation of amyloid beta-protein in transgenic mice expressing low levels of a vasculotropic Dutch/lowa mutant form of amyloid beta-protein precursor. The Journal of biological chemistry 2004, 279( I 9):20296-20306.

10. Miao J, Xu F, Davis J, Otte-Holler I, Verbeek MM, Van Nostrand WE: Cerebral microvascular amyloid beta protein deposition induces vascular degeneration and neuroinflammation in transgenic mice expressing human vasculotropic mutant amyloid beta precursor protein. The American journal of pathology 2005, I67(2):505-515.

II. Fan R, Xu F, Previti ML, Davis J, Grande AM, Robinson JK, Van Nostrand WE: Minocycline reduces microglial activation and improves behavioral deficits in a transgenic model of cerebral microvascular amyloid. J Neurosci 2007, 27( I 2):3057-3063.

12. McGeer EG, McGeer PL: Innate immunity in Alzheimer's disease: a model for local inflammatory reactions. Molecular interventions 200I, I(I):22-29.

13. Strohmeyer R, Shen Y, Rogers J: Detection of complement alternative pathway mRNA and proteins in the Alzheimer's disease brain. Brain research 2000, 8 I(I-2):7-18.

14. Yasojima K, Schwab C, McGeer EG, McGeer PL: Up-regulated production and activation of the complement system in Alzheimer's disease brain. The American journal of pathology 1999, I 54(3):927-936.

15. Wyss-Coray T, Yan F, Lin AH, Lambris JD, Alexander JJ, Quigg RJ, Masliah E: Prominent neurodegeneration and increased plaque formation in complement-inhibited Alzheimer's mice. Proceedings of the National Academy of Sciences of the United States of America 2002, 99( I 6): I 0837-10842.

16. Shen Y, Meri S: Yin and Yang: complement activation and regulation in Alzheimer's disease. Progress in neurobiology 2003, 70(6):463-472.

17. Fonseca MI, Zhou J, Botto M, Tenner AJ: Absence of CIq leads to less neuropathology in transgenic mouse models of Alzheimer's disease. J Neurosci 2004, 24(29):6457-6465.

18. Shen Y, Halperin JA, Benzaquen L, Lee CM: Characterization of neuronal cell death induced by complement activation. Brain research 1997, I(2): 186-194.

19. Rus H, Cudrici C, Niculescu F, Shin ML: Complement activation in autoimmune demyelination: dual role in neuroinflammation and neuroprotection. Journal of neuroimmunology 2006, I 80(1-2):9-16.

20. Shen Y, Li R, McGeer EG, McGeer PL: Neuronal expression of mRNAs for complement proteins of the classical pathway in Alzheimer brain. Brain research 1997, 769(2):391-395.

21. Stoltzner SE, Grenfell TJ, Mori C, Wisniewski KE, Wisniewski TM, Selkoe DJ, Lemere CA: Temporal accrual of complement proteins in amyloid plaques in Down's syndrome with Alzheimer's disease. The American journal of pathology 2000, I 56(2):489-499.

22. Sundaresan S, Roberts PE, King KL, Sliwkowski MX, Mather JP: Biological response to ErbB ligands in nontransformed cell lines correlates with a specific pattern of receptor expression. Endocrinology 1998, I39(1 2):4756-4764.

23. Heid CA, Stevens J, Livak KJ, Williams PM: Real time quantitative PCR. Genome research 1996, 6( I 0):986-994.

24. Eikelenboom P, van Gool WA: Neuroinflammatory perspectives on the two faces of Alzheimer's disease. J Neural Transm 2004, I I I (3):28I-294.

25. Webster SD, Yang AJ, Margol L, Garzon-Rodriguez W, Glabe CG, Tenner AJ: Complement component Clq modulates the 
phagocytosis of Abeta by microglia. Experimental neurology 2000, 16I(I): $127-138$.

26. Tanskanen M, Lindsberg PJ, Tienari PJ, Polvikoski T, Sulkava R, Verkkoniemi A, Rastas S, Paetau A, Kiuru-Enari S: Cerebral amyloid angiopathy in a 95+ cohort: complement activation and apolipoprotein E (ApoE) genotype. Neuropathology and applied neurobiology 2005, 3 I (6):589-599.

27. Webster SD, Tenner AJ, Poulos TL, Cribbs DH: The mouse CIq A-chain sequence alters beta-amyloid-induced complement activation. Neurobiology of aging 1999, 20(3):297-304.

28. Afagh A, Cummings BJ, Cribbs DH, Cotman CW, Tenner AJ: Localization and cell association of $\mathrm{Clq}$ in Alzheimer's disease brain. Experimental neurology 1996, I38(1):22-32.

29. Terai K, Walker DG, McGeer EG, McGeer PL: Neurons express proteins of the classical complement pathway in Alzheimer disease. Brain research 1997, 769(2):385-390.

30. Thiex R, Mayfrank L, Rohde V, Gilsbach JM, Tsirka SA: The role of endogenous versus exogenous tPA on edema formation in murine ICH. Exp Neurol 2004, 189:25-32.

31. Stichel CC, Niermann H, D'Urso D, Lausberg F, Hermanns S, Muller HW: Basal membrane-depleted scar in lesioned CNS: characteristics and relationships with regenerating axons. Neuroscience 1999, 93:321-333.

Publish with Bio Med Central and every scientist can read your work free of charge

"BioMed Central will be the most significant development for disseminating the results of biomedical research in our lifetime. "

Sir Paul Nurse, Cancer Research UK

Your research papers will be:

- available free of charge to the entire biomedical community

- peer reviewed and published immediately upon acceptance

- cited in PubMed and archived on PubMed Central

- yours - you keep the copyright

Submit your manuscript here:

http://www.biomedcentral.com/info/publishing_adv.asp
BiolMedcentral 